\title{
EL DISEÑO DEL MODELO INSTITUCIONAL DE LA PROCURADURÍA GENERAL DE LA REPÚBLICA EN LA EFICIENGIA DE LA DENUNGIA AMBIENTAL
}

\author{
THE DESIGN OF THE INSTITUTIONAL MODEL \\ OF THE ATTORNEY GENERAL OF THE REPUBLIC \\ IN THE EFFICIENCY OF THE ENVIRONMENTAL DENUNCIATION
}

\author{
Laila Alicia Peralta Escobar* \\ Esthela GUTIÉRREZ GARZA** \\ María del Carmen CARMONA LARA ${ }^{* * * *}$
}

REsumen: La Procuraduría General de la República es una institución de orden público que ha sufrido cambios estructurales que fundamentan y explican el comportamiento de la denuncia ambiental. El presente artículo tiene como finalidad el análisis de dichos patrones de comportamiento, de manera cronológica y con vista en su andamiaje institucional hasta su especialización, esto, a través de estadísticas,
ABSTRACT: The Attorney General's Office is an institution of public order that has undergone structural changes that support and explain the behavior of the environmental complaint. The purpose of this article is to analize these patterns of behavior, in a chronological way and focusing on its institucional scaffolding. This article demostrates with data the changes suffered by the environmental complaint within the federative entities of the country.

* Doctoranda en ciencias sociales con orientación en desarrollo sustentable en el Instituto de Investigaciones Sociales (IINSO-UANL), de la Universidad Autónoma de Nuevo León, México. Correo: laila_5555@hotmail.com

** Doctora en sociología e investigadora en el Instituto de Investigaciones Sociales de la Universidad Autónoma de Nuevo León, México (IINSO-UANL). Correo: esthelagutierrez@ gmail.com

**** Doctora en ciencias políticas e investigadora en el Instituto de Investigaciones Jurídicas de la UNAM. Correo: carmona@unam.mx

Boletín Mexicano de Derecho Comparado, nueva serie, año XLIX, núm. 150, septiembre-diciembre de 2017, pp. 1083-1114

Esta obra está bajo una Licencia Creative Commons Atribución-NoComercial-SinDerivar 4.0 Internacional, IIJ-UNAM. 
gráficas y líneas de tiempo, mostrando don datos duros los cambios sufridos por la denuncia ambiental dentro de las entidades federativas del país.

Palabras clave: Diseño institucional, Procuraduría General de la República, denuncia ambiental.
Keyzeords: Institutional design, attorney general, environmental denunciation. 
SUMARIO: I. Introducción. II. Antecedentes del modelo institucional. III. La construcción del modelo institucional de la Procuraduría General de la República y el agente del Ministerio Público de la Federación. IV. El Ministerio Público mexicano ante la procuración de justicia. V. El modelo institucional a través de las fiscalias y unidades especializadas. VI. Análisis estadístico de la denuncia ambiental. VII. Conclusiones. VIII. Fuentes.

\section{INTRODUCGIÓN}

El modelo institucional de la Procuraduría General de la República (en adelante Procuraduría) y la figura del Ministerio Público de la Federación son temáticas de lo más discutidas alrededor del mundo. La transformación que ha convulsionado a nuestro país determina su diseño y construcción, por lo que es digno investigar el grado de eficiencia obtenido dentro de su labor en la obtención de una debida "procuración de justicia".

La presente investigación tiene como objetivo demostrar la hipótesis que versa en que el "modelo institucional de la Procuraduría General de la República incide de manera radical en la eficiencia de la denuncia ambiental"; por tal motivo, es menester analizar su origen y transformación en el devenir histórico. La visión y determinación de nuestros constituyentes fueron modelando sus atribuciones, funciones y alcances con otras entidades similares del país.

La creación de nuevas áreas de trabajo constituye con mayor puntualidad la atención a los delitos en materia ambiental, ya que no existían áreas exclusivas encargadas del tema. Sólo hasta 1991 se creó un parteaguas, y la Procuraduría volcó sus esfuerzos en dirimir de manera "especializada" a través de fiscalías y, posteriormente, en unidades especializadas, el ejercicio de la acción penal, a fin de determinar la presunta responsabilidad del inculpado.

Dentro de este artículo se encuentra un apartado especial que sirve para medir la eficiencia de la denuncia ambiental. Se construye estadística y análisis de resultados mediante gráficas y líneas de tiempo, que denotan el comportamiento de la denuncia ambiental y los estados con mayor representatividad, encontrando sus fortalezas que determinan esta diferencia en la protección de sus recursos naturales. 


\section{ANTECEDENTES DEL MODELO INSTITUCIONAL}

La investidura del procurador general y del fiscal perteneciente a la Suprema Corte se vio delimitada dentro del reglamento del alto tribunal. Éste fue emitido por el presidente Benito Juárez el 29 de julio de 1862. Se determinaba que el fiscal podría ser oído en causas criminales, así como en los negocios pertenecientes a su jurisdicción y competencia en duda de ley ante los tribunales, a petición de parte si la Corte lo estimara procedente. Por otro lado, el procurador general podría intervenir en los asuntos relacionados con hacienda pública, sus derechos o fraude contra ella. La responsabilidad de sus empleados que afectaran a los establecimientos públicos eran temas de su competencia. Estas atribuciones se establecieron en los artículos 64 y demás relativos del Código de Procedimientos Civiles Federales (se equiparó a una especie de ley orgánica del Poder Judicial), emitido el 14 de noviembre de $1895 .^{1}$

Dicha normatividad estableció con puntualidad las funciones tanto del procurador general como del fiscal y de los promotores fiscales. El modelo referido imperó en todas las entidades federativas del país; inició de manera incipiente, poco entendible y deficiente; lo más destacado era su "proceso penal". En ese momento,

la Ley de Jurados para el mismo Distrito y Territorios emitió el 15 de junio de 1869 a tres promotoras fiscales para los tribunales criminales, como parte acusadora, dentro de la averiguación en búsqueda de la verdad procesal penal. ${ }^{2}$

$\mathrm{Al}$ respecto, el ánimo del constituyente dentro de la exposición de motivos era algo imprecisa; no obstante, prevaleció la intención de establecer la influencia española en relación con ciertos elementos del sistema norteamericano similar al Attorney General y del procurador general francés ante la Corte de Casación. La ley secundaria realizó la organización de los tribunales de circuito y los juzgados de distrito en los términos del artículo 96 de la referida ley fundamental. El 11 de octubre de 1861 se estableció por ley a los funcionarios inferiores del Ministerio Público. Además, se

1 Fix-Zamudio, Héctor, Reflexiones sobre el derecho constitucional procesal mexicano, México, Comisión Nacional de Derechos Humanos, 1993, pp. 195-198.

2 Pallares, Jacinto, El Poder fudicial, México, Imprenta del Comercio de Nabor Chávez, reimpresión Tribunal Superior de Justicia del Distrito Federal, 1992, p. 74.

Esta obra está bajo una Licencia Creative Commons

Atribución-NoComercial-SinDerivar 4.0 Internacional, IIJ-UNAM.

Boletín Mexicano de Derecho Comparado, núm. 150, pp. 1083-1114 
asignaron como promotores fiscales a los juzgados y tribunales, por parte del Ejecutivo Federal, en un lapso de cuatro años. ${ }^{3}$

Posteriormente, surge una transición en el modelo institucional dentro del Código de Procedimientos Penales para el Distrito Federal y Territorio de la Baja California el 15 de septiembre de 1880: se retira la figura de los promotores fiscales y se comienza a usar la denominación francesa del Ministerio Público, definido por el artículo 28 como "una magistratura". Esta figura se crea para solicitar y brindar auxilio como garante de la sociedad en la pronta administración de justicia ante los tribunales y con base en la ley. ${ }^{4}$

Catorce años después, dentro del Código, el 15 de septiembre de 1894 se transforma la figura del Ministerio Público en el proceso penal, quien sólo contaba con una postura de un simple auxiliar del juez de instrucción. Dentro del juicio era la parte acusadora, pero carecía del monopolio del ejercicio de la acción penal, puesto que en el proceso intervenían también el ofendido o sus causahabientes, éstos estimados como parte civil. ${ }^{5}$

Existe un gran momento histórico, donde se realiza la separación del procurador general y el fiscal de la tutela de la Suprema Corte. Esto se basó en la reforma al Constituyente de 1857, el 22 de mayo de 1900, en sus artículos 91 y 96: el Ejecutivo era el encargado de nombrar a los funcionarios del Ministerio Público y el procurador General de la República ${ }^{6}$ Este gran paso significó la actual estructura del Ministerio Público y fue emitido a través del Diario Oficial de la Federación del 25 de mayo de 1900, que señalaba a la letra lo siguiente:

Artículo 91. La Suprema Corte de Justicia se compondrá de quince Ministros y funcionará en Tribunal Pleno o en Salas de la manera que establezca la ley.

Artículo 96. La ley establecerá y organizará los Tribunales de Circuito, los Juzgados de Distrito y el Ministerio Público de la Federación. Los funcionarios del Ministerio Público y el Procurador General de la República que ha de presidirlo, serán nombrados por el Ejecutivo. Las reformas ante-

\footnotetext{
3 Pallares, Jacinto, op. cit., pp. 151-156.

4 Fix-Zamudio, Héctor, op. cit., p. 273.

5 Piña y Palacios, Javier, "Origen del Ministerio Público en México", Revista Mexicana de Fusticia, México, enero-marzo de 1984.

6 Ruiz, Eduardo, Derecho constitucional mexicano, 2a. ed., México, Tipografía Aguilar e hijos, 1904, pp. 331 y 332.
} 
riores comenzarán a regir al expirar el período para el que fueron electos los actuales Fiscal y Procurador General.

Después de innumerables cambios estructurales en materia constitucional dentro de la institución del Ministerio Público, surgen legislaciones secundarias encargadas de organizar y estructurar tanto al procurador general como a sus agentes. En 1903 se emite la primera Ley Orgánica del Ministerio Público para el Distrito y Territorios Federales; le reitera la representatividad social, la potestad del Ejecutivo para nombrar a los funcionarios del Ministerio Público y le confiere facultades de intervención en asuntos de interés público con monopolio del ejercicio de la acción penal.

Esta ley (Ley Orgánica del Ministerio Público para el Distrito y Territorios Federales) es el primer intento para hacer práctica la autonomía del Ministerio Público, con relación a las jurisdicciones, y para evitar que siguiera siendo una figura anodina y secundaria que sólo tuviera por objeto fiscalizar la conducta de los jueces y magistrados, aunque fuera de una manera teórica, el Ministerio Público se convierte en el titular del ejercicio de la acción penal. Adquiere la fisonomía propia como representante de la sociedad y evita que los jueces lleven exclusivamente la dirección del proceso. ${ }^{7}$

Posteriormente, en 1908 se expide la Ley Orgánica del Ministerio Público Federal y Reglamento. Este ordenamiento legal le da el carácter al Ministerio Público de auxiliar en la administración de justicia en el ámbito federal de la persecución, investigación y represión de los delitos del orden federal, en defensa de los intereses de la Federación, ante la Suprema Corte de Justicia, tribunales de circuito y juzgados de distrito. No obstante, estas disposiciones legales contaban con defectos de técnica jurídica y funcionamiento que de manera posterior se disminuirán.

7 Franco Villa, J., El Ministerio Público Federal, México, Porrúa, 1985.

Esta obra está bajo una Licencia Creative Commons

Atribución-NoComercial-SinDerivar 4.0 Internacional, IIJ-UNAM.

Boletín Mexicano de Derecho Comparado, núm. 150, pp. 1083-1114 


\section{LA GONSTRUCGIÓN DEL MODELO INSTITUCIONAL DE LA PROCURAdURÍA GENERAL DE LA REPÚBLICA Y EL AGENTE DEL Ministerio PÚblico DE LA FEDERACiÓN}

Contando con un perfil innovador y mixto para su época, e influenciada un tanto por los modelos francés, español y norteamericano, en la Constitución Política de los Estados Unidos Mexicanos de 1917 se erige la figura del Ministerio Público como una instancia independiente, siendo garante de un trabajo de control y vigilancia con el monopolio en la acción penal. Cabe destacar en este apartado, las razones en que se basó Venustiano Carranza en la exposición de motivos presentada ante el Constituyente del 1 de diciembre de 1916 con relación al artículo 21. Esto destaca los principios de seguridad y legalidad jurídica dentro de la etapa de averiguación previa, y son:

a. El abuso de los jueces mexicanos en la averiguación de los delitos y búsqueda de pruebas considerados asaltos contra los reos, para obligarlos a confesar.

b. El Ministerio Público evitará este sistema procesal tan vicioso, restituyendo a los jueces toda la dignidad y toda la respetabilidad de la magistratura.

c. Por otra parte, el Ministerio Público, con la policía judicial represiva a su disposición, quitará a los presidentes municipales y a la policía común la posibilidad de que hasta hoy han tenido de aprehender a cuantas personas juzgan sospechosas, sin más méritos que su criterio particular. ${ }^{8}$

En la redacción del artículo 21 constitucional, ${ }^{9}$ en una introspección en la lectura original y el precepto vigente, cambian las atribuciones judiciales y las ministeriales. A las primeras se les atribuye imponer penas, y a las segundas se les otorga, a su vez, el compromiso de perseguir los delitos con apoyo de la policía a su cargo. Esta simbiosis posibilita al Ministerio Público para que proceda a ejercitar la acción penal, y el juez, en consecuencia, proceda con imparcialidad y legalidad en determinar o no la responsabilidad del procesado en la averiguación previa del nuevo sistema de justicia penal.

8 Burgoa Orihuela, Ignacio, Las garantías individuales, México, Porrúa, 1983, pp. 644648.

9 Véase artículo reformado en el Diario Oficial de la Federación del 3 de febrero de 1983, 31 de diciembre de 1994, 3 de julio de 1996, 20 de junio de 2005 y 18 de junio de 2008.

Esta obra está bajo una Licencia Creative Commons Atribución-NoComercial-SinDerivar 4.0 Internacional, IIJ-UNAM. Boletín Mexicano de Derecho Comparado, núm. 150, pp. 1083-1114 
Otro precepto de igual relevancia para el Ministerio Público es el 102, apartado "A". ${ }^{10}$ Anteriormente, el Ejecutivo con plena libertad podía designar al procurador general (ahora denominado fiscal general). No obstante, en este momento puede proponerlo sólo con la venia del Senado o de la Comisión Permanente.

Existen otras diferencias dignas de mencionar dentro del nuevo sistema de justicia penal en México. Éste era inquisitivo, mixto y acusatorio, y después se transformó en un sistema de justicia acusatorio adversarial, en el que toma relevancia el próximo fiscal general de la República, quien contará con funciones en la fiscalización de las investigaciones denominadas "carpetas de investigación" (aún sin ser nombradas averiguaciones previas), que serán propuestas ante el órgano jurisdiccional, quien finalizará administrando justicia.

A efecto de la reforma constitucional de los artículos 21 y 102 de la Constitución Política de la República de 1917, es posible afirmar que la investidura del Ministerio Público quedó sustanciada en los siguientes preceptos básicos:

a) El monopolio de la acción penal corresponde exclusivamente al Estado, y su ejercicio depende del Ministerio Público;

b) En base al pacto federal, todas las entidades federativas según sus lineamientos constitucionales imponen a la institución del Ministerio Público;

c) Dentro del ejercicio de la acción penal, el Ministerio Público genera las potestades de acción y requerimiento, persiguiendo a los delincuentes, y para que intervenga el juez en materia penal requiere forzosamente la petición oficial por parte del agente ministerial;

d) La policía judicial es coadyuvante del Ministerio Público y se encuentra bajo su cargo en la investigación de los delitos, la búsqueda de las pruebas y el descubrimiento de los responsables;

e) Los jueces en materia penal no cuentan con el carácter de investigador como los policías judiciales, ya que tienen sólo la encomienda de funciones decisorias;

f) No es procedente que los agraviados en su carácter de querellantes o denunciantes busquen directamente la protección de los jueces, es requisito

10 Véase apartado reformado en el Diario Oficial de la Federación del 28 de enero de 1992, 31 de diciembre de 1994 y 10 de febrero de 2014. Constitución Política de los Estados Unidos Mexicanos, 2014.

Esta obra está bajo una Licencia Creative Commons

Atribución-NoComercial-SinDerivar 4.0 Internacional, IIJ-UNAM.

Boletín Mexicano de Derecho Comparado, núm. 150, pp. 1083-1114 
indispensable que intervenga el Ministerio Público, a fin de que promueva según la ley la acción penal correspondiente. ${ }^{11}$

\section{EL Ministerio PÚblico MEXiCANO ANTE LA PROGURACIÓN DE JUSTICIA}

El Ministerio Público cuenta con otras facultades diferentes a las que se ha hecho referencia con anterioridad. El artículo 4o. de la Ley Orgánica de la Procuraduría General de la República señala tres apartados, que se sintetizan en las siguientes temáticas: acciones ante los órganos jurisdiccionales, además de ejercer acción penal ante los jueces puede solicitar órdenes de cateo; pone a disposición a personas detenidas o aprehendidas; aporta pruebas, formula conclusiones e impugna términos; atención a la víctima o el ofendido, les proporciona asesoría, recibe elementos de prueba, solicita la reparación del daño, protege a los menores para que se abstengan a los careos, interviene como parte en los juicios de amparo, y, por último, asuntos de interés y trascendencia para la Federación, interviene en donde sean parte los cónsules generales y diplomáticos, en asuntos de extradiciones o entrega de indiciados, procesados o sentenciados y requiere informes, documentos, opiniones y elementos de prueba de las dependencias y entidades de la administración pública federal. ${ }^{12}$

Es evidente que las atribuciones que se han señalado y que están inmersas hacia el agente del Ministerio Público se enmarcan en una máxima que se utiliza en reiteradas ocasiones: "procuración de justicia", ${ }^{13}$ debiendo distinguirla de otro paradigma que se utiliza con poca reflexión jurisdiccional, y que se expresa como "impartición de justicia". ${ }^{14}$

Es por esto que la idea de "procuración de justicia” tiene una connotación holística, ya que puede aplicarse a todos los organismos del Estado que realizan trabajos de gestoría, investigación y representación de los intereses de la sociedad en coadyuvancia con los tribunales, por lo que se

11 Castro, Juventino V., El Ministerio Público en México, funciones y disfunciones, 7a. ed., México, Porrúa, 1990.

12 La Ley Orgánica de la Procuraduría Federal de la República fue emitida a través del Diario Oficial de la Federación del 27 de diciembre de 2002, dentro del mandato del presidente Vicente Fox Quesada.

13 Castro Juventino, J., op. cit., pp. 121-211.

14 Fix-Zamudio, Héctor, op. cit., pp. 358-365.

Esta obra está bajo una Licencia Creative Commons Atribución-NoComercial-SinDerivar 4.0 Internacional, IIJ-UNAM. Boletín Mexicano de Derecho Comparado, núm. 150, pp. 1083-1114 
encuentra limitada dicha denominación, dejando a un lado las amplias facultades que se le otorgan al Ministerio Público en México.

Referente a la etapa de la averiguación previa (ahora carpeta de investigación), es fundamental integrarla con la mayor precisión y base jurídica, ya que las inconsistencias dentro de la investigación permean de manera sensible en el proceso penal ante el juez de la causa. Posteriormente, en el proceso penal, el agente ministerial es la parte acusadora y debe aportar todos los medios probatorios que la ley le permita, para probar la materialización del hecho imputado. Se dirime la responsabilidad penal del procesado presentando su acusación y pretensiones.

Una vez cerrada la instrucción y abierta la etapa de pliego de las llamadas "conclusiones", que son los alegatos finales, y en los que puede variar fundamentalmente la calificación de los hechos delictuosos e inclusive solicitar, por medio del desistimiento expreso o de las llamadas conclusiones no acusatorias, el sobreseimiento definitivo de la causa, subsecuentemente se dicta la sentencia correspondiente. ${ }^{15}$

Causa polémica la doble función de autoridad y parte del agente ministerial en la doctrina, así como de la hermenéutica de la ley. La facultad exclusiva en el ejercicio de la acción penal y su intervención como parte en el proceso penal excluye la participación del ofendido o sus causahabientes en calidad de parte en el mismo proceso que se admite a otros ordenamientos. ${ }^{16} \mathrm{Al}$ respecto, existen dos puntos de vista contrarios; el primero está representado por el destacado tratadista Sergio García Ramírez, quien excluye la participación del ofendido en el proceso penal, por considerar que propiciaría el riesgo de inspiración indicativa en el ejercicio penal, en tanto que el Ministerio Público es el representante de la sociedad y actúa con objetividad. ${ }^{17}$

Los agentes de Ministerio Público de la Federación, de manera general, han contado dentro de sus filas con un inumerable personal. Por tanto, se presenta una muestra representativa en línea de tiempo del fluctuante comportamiento, como se señalan en la gráfica 1, ya que la Procu-

15 García Ramírez, Sergio, Proceso penal y derechos humanos, 2a. ed., México, Porrúa, 1993, pp. 636-641.

16 Fairén, Guillén, Teoría general del derecho procesal, México, UNAM, 1992, pp. 87-89; Castillo Soberanes, Miguel Ángel, El monopolio del ejercicio de la acción penal del Ministerio Público en México, México, UNAM, 1991, pp. 41-54; Castro Juventino, J., op. cit., pp. 121-128.

17 Castro Juventino, J., op. cit., p. 211. 
Esta revista forma parte del acervo de la Biblioteca Jurídica Virtual del Instituto de Investigaciones Jurídicas de la UNAM

raduría en 1994 presenta sesenta agentes, teniendo su punto más elevado en el 2007, con 1,794, y en 2010 baja un poco a 1,693.

\section{Gráfica 1. Línea de tiempo de agentes del Ministerio Público Federal}

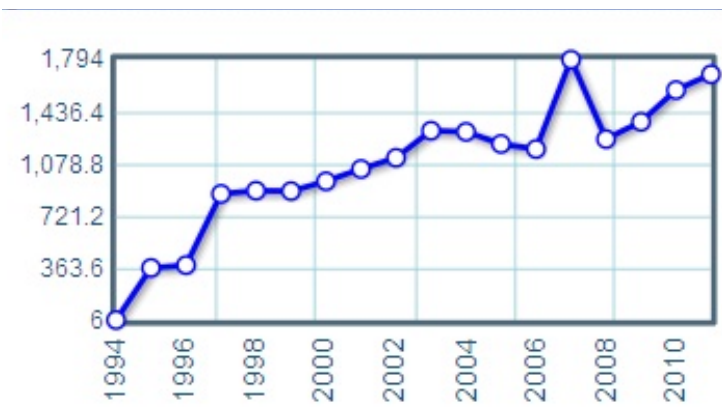

FUENTE: Instituto Nacional de Estadística y Geografía. ${ }^{18}$

\section{EL MODELO INSTITUGIONAL A TRAVÉS \\ DE LAS FISCALÍAS O UNIDADES ESPECIALIZADAS}

En los ochenta, el procurador general de la Procuraduría General de la República emitió el Reglamento de la Ley Orgánica de la Procuraduría publicada en el Diario Oficial de la Federación del 8 de marzo de 1985. La organización general consistía en nombrar dos subprocuradurías, una oficialía mayor, una visitaduría general, una contraloría interna y trece unidades de rango de dirección general.

Dentro del Plan Nacional de Desarrollo del presidente Miguel de la Madrid Hurtado, en 1984, el procurador general expidió el Acuerdo 7/84, donde crea nuevas áreas, desconcentrando sus funciones administrativas; establece delegaciones de circuito y once agencias del Ministerio Público fuera de la zona metropolitana del Distrito Federal. ${ }^{19}$ Dentro de la procuración de justicia en nuestro país, hace varias décadas se creó

18 Las gráficas 1 y 2 fueron obtenidas a través del Instituto Nacional de Estadística y Geografia, disponible en: 20http://buscadorinegi.org. $\mathrm{m} x /$ search $?$ t $x=P G R \mathcal{E}^{2} q=P G R \mathcal{E}^{2}$ site $=$ sitioIN

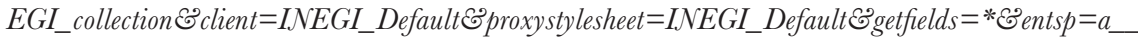
inegi_politica\&Proxyreload $=1$ \&lr=lang_es\%257Clang_en Elr=lang_es\%257Clang_en Effilter $=1$.

19 Procuraduría General de la República en inicio de unidades especializadas, disponible en: http://wrwr.pgr.gob.mx/Unidades-Especializadas/Paginas/default.aspx. 
por primera vez en nuestra historia una Fiscalía Especializada en Asuntos Ecológicos, por parte del procurador general de la República, licenciado Ignacio Morales Lechuga, mediante Acuerdo 21/91, y la denominó "Fiscalía Forestal".

Esta fiscalía se perfeccionó por medio del Acuerdo 26/91, en donde se veían asuntos referente a la flora. En aquel entonces no existían operativos, y sólo había pocas mesas para diligenciar los problemas ambientales. Agregado a lo anterior, imperaban las deficiencias de las leyes ambientales, sujetando la justicia ambiental al Código Penal Federal. Subsecuentemente, y a la par, existió la Fiscalía Especial en Delitos Patrimoniales y de Propiedad Intelectual; el 15 de febrero de 1994 se desmembró y se dividió en tres. Dio cabida a la Fiscalía Especial en Delitos Patrimoniales Fiscales y de Banca; a la Fiscalía Especial a Derechos de Autor, y a la Fiscalía Especial para Delitos Ecológicos, a los que posteriormente se les incorporó la temática de carreteros.

Esta fiscalía contaba con un mayor número de mesas, y se realizaban operativos tanto en flora como en fauna, utilizando el auxilio de agentes del Ministerio Público de la Federación de otras fiscalías. Dentro de los operativos en el diseño de su logística participaban una serie de autoridades de las tres esferas de gobierno, tanto federales como del fuero común.

La fiscalía en comento operó hasta septiembre de 1997; tiempo después, prosiguió su reestructuración, creándose un nuevo organismo mediante el acuerdo 70/98, por parte del procurador general de la República, Jorge Madrazo Cuéllar, el 29 de julio del mismo año, y ostenta el nombre de "Fiscalía Especializada para la Atención a los Delitos Ambientales". Cabe señalar que las mesas en materia ambiental se han multiplicado en todas las delegaciones de la Procuraduría y se han incrementado en conocimiento y eficacia.

Dos años antes, el 27 de agosto de 1996, el procurador general emitió un nuevo reglamento de la Procuraduría, donde da cabida de cinco a seis subprocuradurías de Coordinación General y Desarrollo, Jurídico y Asuntos Internacionales. Asimismo, subprocuradurías de Procedimientos Penales A, B y C. Éstos aglutinaron a seis direcciones generales y 32 delegaciones estatales. Se creó la Fiscalía Especializada para la Atención a los Delitos contra la Salud en sustitución del Instituto Nacional para el 
Combate a las Drogas (INCD). Además, se adhieren las unidades especializadas en delincuencia organizada y contra el lavado de dinero. ${ }^{20}$

A través del Diario Oficial de la Federación del 28 de abril de 2009, en su quinta sección, y con fundamento en los artículos 9o. de la Ley Orgánica de la Procuraduría General de la República y el artículo 5o. de su reglamento y 19 de la Ley Orgánica de la Administración Pública Federal, el procurador expide el "Manual de Organización General de la Procuraduría General de la República", en donde se crea la Subprocuraduría Especializada en Investigación de Delitos Federales. Ésta cuenta con cuatro unidades, donde destaca la denominada "Unidad Especializada en Investigación de Delitos contra el Medio Ambiente y Previstos en Leyes Especializadas" (en adelante, la UEIDAPLE).

La UEIDAPLE representa a la sociedad en la investigación y persecución de delitos en materia federal, apelando a los principios de legalidad, honradez, eficacia, seguridad y certeza jurídica, en apoyo a una estructura funcional de la procuración de justicia y las condiciones del ciudadano en pro al desarrollo integral del Estado de derecho. Las premisas de trabajo versan en el fomento a la cultura de la denuncia ciudadana, dando tres meses desde su inicio para emitir su determinación basada en la honestidad. $^{21}$

En la Procuraduría tuvimos la oportunidad de contactarnos con el licenciado José Ricardo Rodríguez Soria, director de la Unidad Especializada en Investigación de Delitos contra el Medio Ambiente y Previstos en Leyes Especializadas (UEIDAPLE), figura 1, quien habla abiertamente del modelo institucional de la Procuraduría, y señala que sus funciones, entre otras, son de gabinete, de escritorio y trabajo de campo en operativos. Es una fiscalía especializada y operativa, en donde se realizan inspecciones ministeriales en la zona, en compañía de peritos especializados en materia forestal, criminalística, fotografía y medio ambiente, y otros según la materia.

20 Procuraduría General de la República, información obtenida en las unidades especializadas, disponible en: http://wrere.pgr.gob.mx/Unidades-Especializadas/Paginas/default.aspx.

21 Procuraduría General de la República en unidades especializadas en investigación de delitos contra el ambiente y previsto en leyes especiales, disponible en: http://wrwr.pgr. gob.mx/Unidades-Especializadas/uedmatpa/Paginas/default.aspx. 
Esta revista forma parte del acervo de la Biblioteca Jurídica Virtual del Instituto de Investigaciones Jurídicas de la UNAM

\section{FIgURA 1. Foto de José Ricardo Rodríguez Soria}

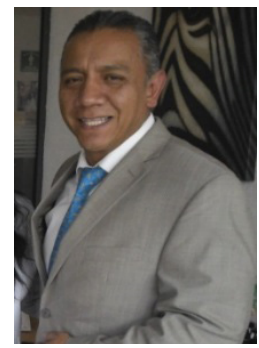

FUENTE: elaboración propia.

Contamos con datos actuales del modelo institucional de la Procuraduría en su infraestructura ambiental proporcionados por el licenciado Rodríguez Soria, quien señala:

...el país va creando las instituciones de acuerdo a las necesidades que se tiene, en este caso en materia ambiental y va creando sus modelos. Tenemos la Secretaría de Medio Ambiente y Recursos Naturales, SEMARNAT, contamos con la PROFEPA, la misma PGR a través de esta unidad y bajo este contexto estas autoridades nos vamos coordinando en todos los ámbitos de gobierno. Si bien es cierto que nosotros, hablando de las autoridades que mencioné, estamos en el ámbito federal, también participan el ámbito estatal y el ámbito municipal ese a mi juicio es nuestro modelo institucional. Pero ahí tendríamos que ver cómo va participando cada uno de los poderes para poder decir que estamos en un contexto de coordinación. Nosotros en el 2004 celebramos un convenio de colaboración entre SEMARNAT, PROFEPA y PGR para la atención de delitos contra el ambiente, en este convenio de colaboración a la fecha PROFEPA y PGR participan activamente día a día. Lo que quiere decir que trabajamos en acciones operativas, nos coordinamos con peritos de PROFEPA. La PGR atiende las denuncias que presenta la PROFEPA. Coordinando acciones de investigación, tenemos reuniones de trabajo, con un grupo implementado precisamente para este tipo de acciones, pero ese es de nosotros dos, la participación de SEMARNAT. En algún momento no es tan notoria, será probablemente porque ellos son más administrativos y más enfocados a la cuestión de investigación de delitos contra el ambiente...

... a raíz de la reestructuración que tiene la PGR en 2003 se crean varias subprocuradurías y dentro de ellas está la subprocuraduría especializada en

Esta obra está bajo una Licencia Creative Commons

Atribución-NoComercial-SinDerivar 4.0 Internacional, IIJ-UNAM.

Boletín Mexicano de Derecho Comparado, núm. 150, pp. 1083-1114 
investigación de delitos federales. Esta subprocuraduría a su vez se encarga de la integración o perfeccionamiento de investigaciones precisamente en materia de delitos federales creándose cuatro unidades. Una de ellas es la Unidad de delitos fiscales y financieros, otra es la Unidad de delitos de piratería, otra es la Unidad de delitos cometidos por servidores públicos y tenemos la Unidad especializada en la investigación de delitos contra el ambiente y previstos por leyes especiales. Esta unidad tiene a su cargo toda la investigación en materia ambiental, es competente para conocer de todos los delitos contra el ambiente de los cuales están previstos en el titulo vigesimoquinto del código penal federal. Tiene un titular, dos direcciones de área una de ella encarga de delitos contra el ambiente y la otra es la dirección de delitos previstos en leyes especiales. En específico la Unidad de delitos contra el ambiente tiene a su cargo trece mesas de trámite a cargo de oficiales del Ministerio Público de la Federación que están especializados en materia ambiental. Tenemos a nuestro cargo a nivel nacional el conocer todos los delitos que atenten contra el medio ambiente y que se encuentren previstos en el titulo vigesimoquinto del código penal federal...

Por otro lado, en general, el modelo institucional de la Procuraduría, a través de las agencias ministeriales del fuero federal, ha sufrido reestructuraciones en su andamiaje, como se ha señalado en la gráfica 2. Para establecer una muestra de lo referido, se presenta una línea de tiempo desde 1994 a 2010, ya que las agencias en México en 1994 contaban con 171, teniendo su punto más elevado en 1996 con 276 y en 2010 descienden a 157.

GRÁfICA 2. Línea de tiempo de agencias del Ministerio Público Federal

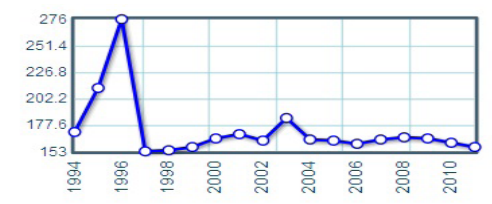

\begin{tabular}{ll}
$\begin{array}{l}\text { Total } \\
\text { nacional }\end{array}$ & 2011 \\
\hline Valor & 157 \\
\hline Fuente & $\begin{array}{l}\text { PGR. Procuraduría General de la República. Datos referidos al } 31 \text { de diciembre de } \\
\text { cada año. }\end{array}$ \\
\hline
\end{tabular}

FUENTE: Instituto Nacional de Estadística y Geografía.

Esta obra está bajo una Licencia Creative Commons Atribución-NoComercial-SinDerivar 4.0 Internacional, IIJ-UNAM. Boletín Mexicano de Derecho Comparado, núm. 150, pp. 1083-1114 


\section{ANÁLISIS ESTADÍSTICO DE LA DENUNCIA AMBIENTAL}

En esta parte de la investigación establecemos los índices delictivos reflejados de las denuncias ambientales por entidad federativa. Las denuncias se analizan en un rango de tiempo de 2007 a 2014. La información se obtuvo de la página oficial de la Procuraduría. Con esta información se realizaron gráficas de la estadística que la representa; se observa con detalle la condición en cada entidad federativa, y se destaca el estado con mayor representatividad.

La hipótesis que se pretende demostrar versa en que el "Modelo institucional de la Procuraduría General de la República incide de manera radical en la eficiencia de la denuncia ambiental". A fin de obtener mayor información acerca de cuáles son los detonantes que han generado estas particularidades, vemos con detalle cuáles son los agentes que se han involucrado en cada estado de la República, en particular, y cómo las delegaciones de la Procuraduría se han comportado dentro de su diseño institucional.

Comenzamos en 2007; el estado representativo es Sinaloa (gráfica 3). La entidad cuenta con una gran riqueza en recursos naturales y minerales, enmarcada con diversos microclimas, una gran cordillera de montañas de bosques de coníferas, así como de selvas; su orografía se ve reflejada, entre otras, con la Sierra Madre, así como de vastos kilómetros de costas en el mar de Cortés, caracterizándose por su gran abundancia de cuerpos de agua.

Sinaloa, como estado representativo de los delitos del fuero federal en materia ambiental, consta de 148 denuncias. Estos resultados se obtuvieron en el cómputo de enero a diciembre con un número total de datos de 1,397. Los estados que le siguen de cerca esta representatividad, y que son ejemplos más adelante, son Veracruz, con 134 denuncias, y Michoacán, con 120 denuncias, respectivamente.

Según los reportes de la Procuraduría en su portal histórico, del 9 de enero de 2007, a través de su boletín 010/07, ${ }^{22}$ se celebró una junta de trabajo entre los sectores productivos, fuerzas políticas y organizaciones civiles.

22 Procuraduría General de la República en su portal histórico, sala de prensa, evento donde se reunieron sectores sociales y legisladores con titulares de la Procuraduría y la Secretaría de Seguridad Social en Sinaloa, disponible en: http://archivo.pgr.gob.mx/Prensa/2007/bol07/Ene/b01007.shtm.

Esta obra está bajo una Licencia Creative Commons

Atribución-NoComercial-SinDerivar 4.0 Internacional, IIJ-UNAM.

Boletín Mexicano de Derecho Comparado, núm. 150, pp. 1083-1114 
Esta revista forma parte del acervo de la Biblioteca Jurídica Virtual del Instituto de Investigaciones Jurídicas de la UNAM

Esto a fin de externar las particularidades locales que sean reflejadas en respuestas conjuntas, en acciones con inteligencia, prudencia y eficacia en la obligada coordinación entre los diferentes sectores. Esta reunión cuenta con el objetivo fundamental de organizarse para combatir la criminalidad con la inteligencia social, reflejada en "demandas ciudadanas". ${ }^{23}$ Lo anterior explicaría el detonante que representó un cambio entre las diferentes estructuras de órganos de gobierno con la directa participación ciudadana.

GrÁficA 3. Delitos ambientales, Sinaloa 2007

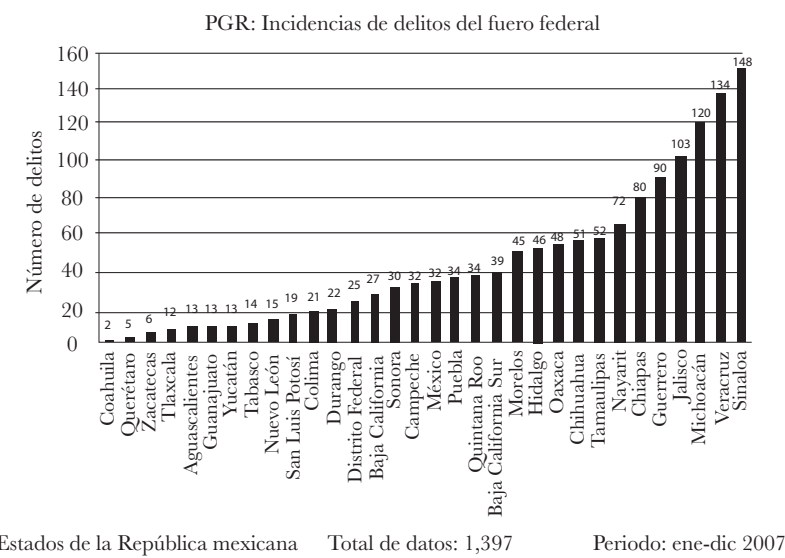

FUENTE: elaboración propia. ${ }^{24}$

23 Los sectores sociales demandan al principio la intervención directa de la Procuraduría en su delegación estatal. Esta instancia se encuentra encabezada por el licenciado Eduardo Medina Mora Icaza. Además, se reunieron otras autoridades, el gobernador del estado de Sinaloa, licenciado Jesús Aguilar Padilla, por la Secretaría de Seguridad Pública, el licenciado Genaro García Luna, los diputados locales por el PRI, Jesús Burgos Pinto, por el PAN, Guadalupe Robles y por el PRD, Feliciano Castro Meléndez y de la Confederación de Asociaciones Agrícolas del estado, Juan Enrique Haberman, entre otras.

24 * Las gráficas que se encuentran en esta sección del artículo se han construido con base en la estadística proporcionada por la Procuraduría General de la República, en el apartado de incidencia delictiva del fuero federal (IDEF). De todos los delitos de orden federal se escogieron los ambientales y se construyeron tablas, que se graficaron y que se exponen en la presente investigación, disponible en: http://wrere.pgr.gob.mx/temas\%20relevantes/ estadistica/Incidencia\%20Entidad/IDEF.asp. 
Por otra parte, la Procuraduría, a través del Boletín 552/08, del 6 de julio de 2008, expone información relevante sobre el incremento de la incidencia delictiva en todo el país y pone de manifiesto que estos datos son el primer eslabón en la cadena de la procuración de justicia del ámbito federal. Reporta que en el periodo 2004-2005 se incrementa en un 9.8\%, en el 2005-2006 aumenta a un 22.45\%, en 2006-2007 en un 25.23\%; en general de 2004 a 2007 sube a un $68.37 \%$, figura $1 .{ }^{25}$ Aunque no señala los delitos ambientales, en particular, los incluye en un contexto general, señalando los delitos con mayor reincidencia, los delitos cometidos contra la salud, los cometidos en contra de la Ley Federal de Armas de Fuego y Explosivos, los delitos patrimoniales, los cometidos por servidores públicos, los cometidos en detrimento a la Ley Federal contra la Delincuencia Organizada y de la Ley General de Población. ${ }^{26}$

FIGURA 2. Mapa del índice delictivo de los delitos del fuero federal PGR (2007 a 2008)

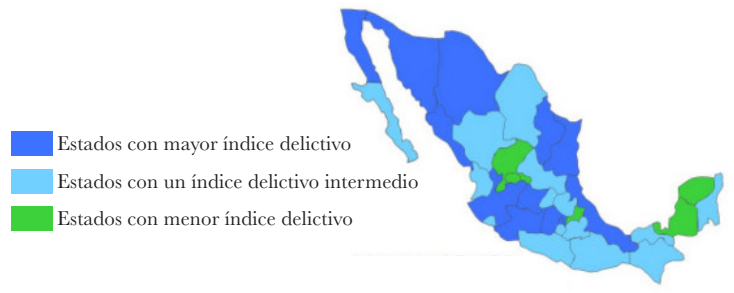

FuenTE: Procuraduría General de la República, portal histórico.

25 Las entidades federativas con un mayor número de delitos denunciados del orden federal son: Jalisco, Distrito Federal, Baja California, Guanajuato, Sonora, Sinaloa, México, Michoacán, Nuevo León, Veracruz, Chihuahua y Tamaulipas. En un punto intermedio, en orden de menor a mayor incidencia se tienen los estados de Tabasco, Querétaro, Colima, Coahuila, San Luís Potosí, Durango, Oaxaca, Quintana Roo, Hidalgo, Baja California Sur, Morelos, Puebla, Nayarit, Chiapas y Guerrero. El menor número de delitos registrados los encontramos en los estados de Tlaxcala, Campeche, Yucatán, Zacatecas y Aguascalientes. Información obtenida del portal histórico de la Procuraduría General, disponible en: http: //archivo.pgr.gob.mx/Prensa/2007/bol08/ful/b552\%2008.shtm, 13 de septiembre de 2015.

26 Procuraduría General de la República en incidencias delictivas del fuero federal (IDEF), http://wrwre.pgr.gob.mx/temas\%20relevantes/estadistica/Incidencia\%20Entidad/IDEFasp.

Esta obra está bajo una Licencia Creative Commons

Atribución-NoComercial-SinDerivar 4.0 Internacional, IIJ-UNAM.

Boletín Mexicano de Derecho Comparado, núm. 150, pp. 1083-1114 
Continuando con el análisis de las entidades del país con mayores denuncias ambientales, en 2008, 2010 y 2011 , Veracruz repunta su interés de la denuncia ambiental; esta entidad federativa tutela una gran riqueza en recursos naturales, que se ve reflejada en flora y fauna, ubicadas en parques nacionales y reservas naturales. Cuenta con un sistema arrecifal (arrecife coralino y pastos marinos), circunscritos por grandes cuerpos de agua. Su orografía está representada por una franja de tierra angosta y alargada de norte a sur entre la Sierra Madre Oriental y el golfo de México.

Este estado es el que cuenta con mayor representatividad en esta investigación, ya que encabeza el mayor número en denuncias ambientales de 135,107 y 142 en 2008, 2010 y 2011, respectivamente, (gráficas 4, 5 y 6). Los delitos ambientales que se presentan con mayor frecuencia es la contaminación de suelo, aire y agua, delitos contra la flora y la fauna, y la tala clandestina.

Veracruz reflejó su preocupación por el deterioro de todos sus recursos naturales. La problemática de mayor incidencia es la disminución de su cobertura vegetal en las cuencas o microcuencas que sufren deforestación, degradación de suelos y contaminación, entre otras.

En consecuencia, el estado implementó medidas a través de la creación del Programa Veracruzano del Medio Ambiente (en adelante PVMA).27 Esta política pública fue propuesta e instaurada en 2005 dentro del mandato del licenciado Fidel Herrera Beltrán, en su carácter de gobernador del estado, por medio de su Plan Veracruzano de Desarrollo 2005-2010. Dicho instrumento político fue estratégicamente aplicado en forma transversal en todas las obras, acciones y políticas de gobierno, a fin de incluir los insumos naturales básicos, el pago de servicios ambientales para la orientación hacia la sustentabilidad del estado.

El PVMA tiene como objetivo diseñar e implementar estrategias de la adecuada aplicación de la ley, creación de nuevas normativas ambientales en la prevención de los delitos ambientales, la tipificación de algunas conductas sociales nocivas al ambiente como delitos ambientales y ser castigados con mayor severidad, en la disminución de los índices de de-

27 Gobierno del Estado de Veracruz, por parte del Consejo Estatal de Protección al Ambiente, disponible en: http://www.veracruz.gob.mx/finanzas/files/2012/01/tfo7-pe-podmedio-ambuente.pdf. 
Esta revista forma parte del acervo de la Biblioteca Jurídica Virtual del Instituto de Investigaciones Jurídicas de la UNAM

gradación en la protección al ambiente y los recursos naturales del estado. Contempla doce ejes estratégicos: información ambiental, biodiversidad, manejo integral de agua, bosques y cuencas, turismo sostenible, servicios ambientales, educación ambiental, ordenamiento territorial, residuos peligrosos y no peligrosos, legislación y justicia ambiental, fortalecimiento transversal e investigación y desarrollo tecnológico.

A este respecto, existe un precedente en el contexto institucional, ya que a solicitud del órgano Legislativo, en 2008 se le solicitó a la Procuraduría y a otras entidades, que tienen que ver con la inspección y vigilancia de la tala clandestina y los cambios de uso forestal en el territorio nacional, realizar acciones encaminadas a fin de minimizar este tipo de delitos. ${ }^{28}$

Gráficas 4, 5 y 6. Delitos ambientales

Veracruz $(2008,2010$ y 2011$)$

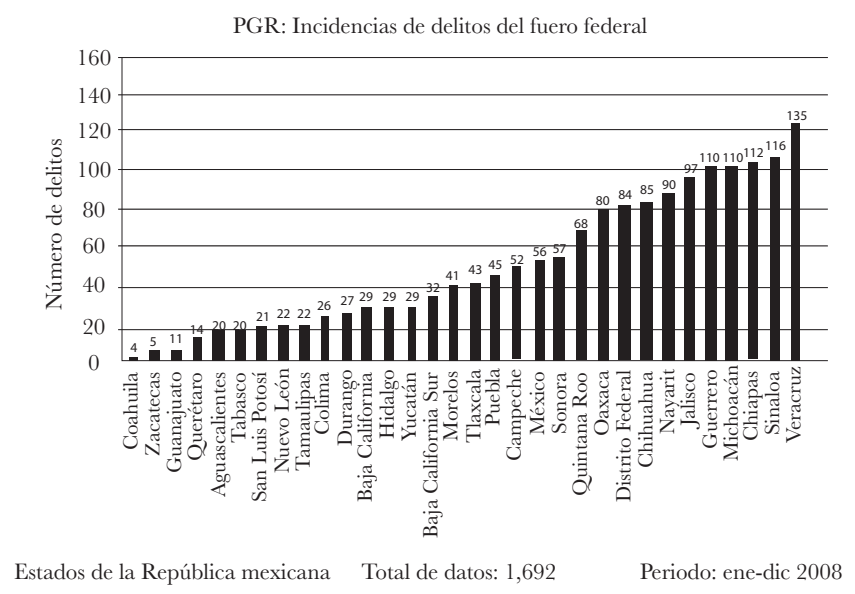

28 La iniciativa en comento es a través del D.G.P.L. 60-II-4-915, signado por las diputadas Ruth Zavaleta Salgado y Patricia Villanueva Abraján, presidenta y secretaria, respectivamente, de la mesa directiva de ese órgano legislativo. Este punto de acuerdo lo da a conocer Oscar Pimentel González, director general de Políticas Públicas y Coordinación Interinstitucional, mediante oficio del 3 de enero de 2008, informando las instrucciones instauradas por parte de la licenciada Claudia Ruiz Massieu Salinas en su carácter de coordinadora de Planeación, Desarrollo e Innovación Institucional en respuesta a su oficio SEL/300/4780/07, comunicando la aprobación de la Cámara de Diputados sobre este tenor.

Esta obra está bajo una Licencia Creative Commons

Atribución-NoComercial-SinDerivar 4.0 Internacional, IIJ-UNAM.

Boletín Mexicano de Derecho Comparado, núm. 150, pp. 1083-1114 
Esta revista forma parte del acervo de la Biblioteca Jurídica Virtual del Instituto de Investigaciones Jurídicas de la UNAM http://www.juridicas.unam.mx/ https://biblio.juridicas.unam.mx/bjv https://revistas.juridicas.unam.mx/ DOI: http://dx.doi.org/10.22201/iij.24484873e.2017.150.11834

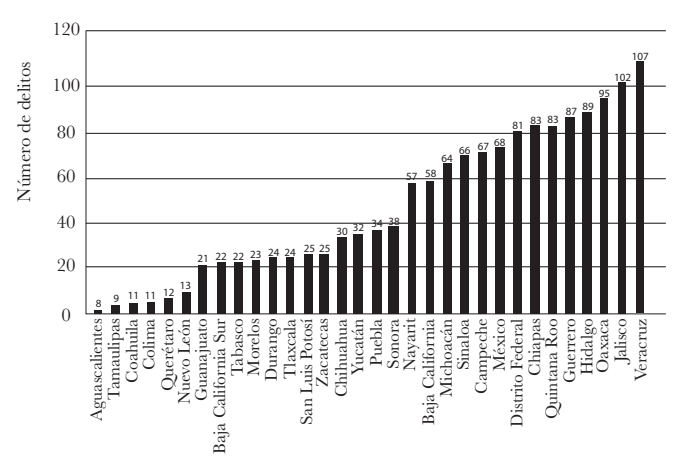

Estados de la República mexicana Total de datos: 1,491 Periodo: ene-dic 2010

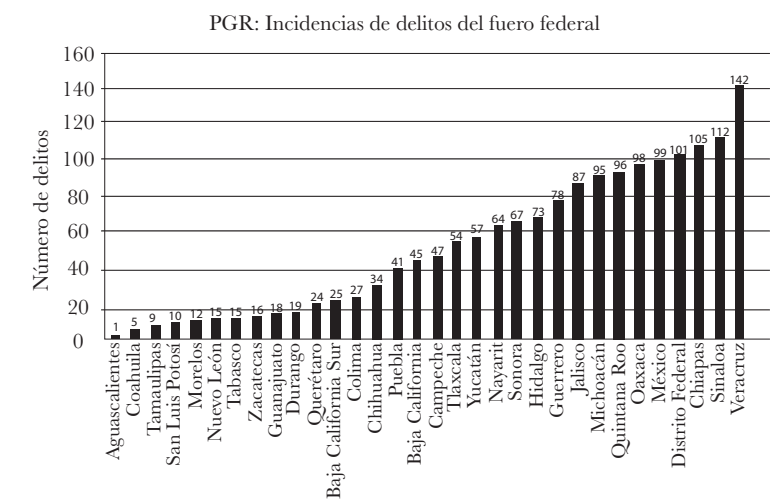

Estados de la República mexicana Total de datos: 1,692 Periodo: ene-dic 2011

FUENTE: elaboración propia.

En este punto de acuerdo se establecieron compromisos específicos para su cumplimentación por parte de las delegaciones estatales de la Procuraduría, en coadyuvancia con las autoridades federales, estatales y municipales. Son veinticinco ${ }^{29}$ las entidades de la República que cuentan con esas acciones, en particular ${ }^{30}$ para su implementación en las delegaciones referidas. El caso de Veracruz es el siguiente:

${ }^{29}$ La entidades federativas referidas son: Aguascalientes, Baja California, Baja California Sur, Campeche, Coahuila, Colima, Chiapas, Jalisco, Michoacán, Morelos, Nayarit, Nuevo León, Oaxaca, Puebla, Querétaro, Quintana Roo, San Luis Potosí, Sinaloa, Sonora, Tabasco, Tamaulipas, Tlaxcala, Veracruz, Yucatán y Zacatecas. Por medio de esta investigación se establecerán los compromisos de los estados representativos de este estudio.

30 Secretaría de Gobernación, documentos de sus archivos, disponibles en: http://sil. gobernacion.gob.mx/Archivos/Documentos/2008/02/asun_2411656_20080212_1202840096.pdf.

Esta obra está bajo una Licencia Creative Commons Atribución-NoComercial-SinDerivar 4.0 Internacional, IIJ-UNAM. Boletín Mexicano de Derecho Comparado, núm. 150, pp. 1083-1114 
-Estrecha comunicación con los policías preventivos y el ejército mexicano.

- Conferencias periódicas respecto a la prevención de delitos ambientales.

-Operaciones carreteras o localización de aserraderos clandestinos.

- El personal ministerial actuará con rapidez y eficacia en las denuncias formuladas por la Profepa o la Semarnat, así como por particulares.

- Puntos de revisión a fin de detectar productos de tipo forestal que no cuenten con la documentación correspondiente.

Los instrumentos políticos en comento han producido directamente una gran influencia en la calidad de la denuncia ambiental del estado de Veracruz. Esto explica que han sido punta de lanza en el país representando un ejemplo en el diseño de estrategias públicas.

Continuando con el análisis, le toca el turno a Michoacán, que cuenta con un clima templado; su orografía es de las más accidentadas del país, y es enmarcada con numerosos volcanes que conforman el eje volcánico transversal y la Sierra Madre del Sur. Tiene en su haber diferentes cuerpos de agua, entre ellos ríos y lagos; la vegetación con mayor representatividad son la agrícola y la selva. Bajo ese tenor, el estado tiene varios parques y reservas naturales. Destaca la mariposa monarca, que se ha convertido en un símbolo emblemático en instrumentos jurídicos internacionales como el Tratado de Libre Comercio.

En 2009 y 2010, Michoacán y otros estados ${ }^{31}$ realizaron reuniones de análisis y estudios de delitos ambientales. Las acciones a seguir consistían en homologar criterios sobre la tipificación de delitos ambientales, planteamiento de normas en operativos ambientales regionales, capacitación mínima en la materia e implementar operativos forestales en la zona centro del país. A fin de concretar dichos esfuerzos, reactivaron la Procuraduría Federal de Protección al Ambiente y la Procuraduría General de la República, mediante la firma de un convenio de colaboración para el combate de los delitos ambientales. Se constituye un comité técnico especializado en delitos ambientales con una postura de "cero tolerancia" en las transgresiones de la ley. Además, implementan la modalidad de

31 Dentro de este estudio se encuentran otros estados, como el estado de México, Veracruz, Chiapas y Sinaloa.

Esta obra está bajo una Licencia Creative Commons

Atribución-NoComercial-SinDerivar 4.0 Internacional, IIJ-UNAM.

Boletín Mexicano de Derecho Comparado, núm. 150, pp. 1083-1114 
Esta revista forma parte del acervo de la Biblioteca Jurídica Virtual del Instituto de Investigaciones Jurídicas de la UNAM

"tentativa" para que las autoridades presumible y científicamente puedan configurar la figura legal y procedan en consecuencia. Realizan una fuerte campaña de difusión a través de trípticos denominados "Prevención de delitos ambientales", a efecto de evitar el daño ambiental, la tala de árboles, el cuidado de encender fogatas en los bosques, descartar la compra y captura de animales silvestres, evitar la caza y pesca de manera ilegal, así como los delitos industriales en general (gráfica 7). ${ }^{32}$

GráfiCa 7. Delitos ambientales, Michoacán (2009)

PGR: Incidencias de delitos del fuero federal

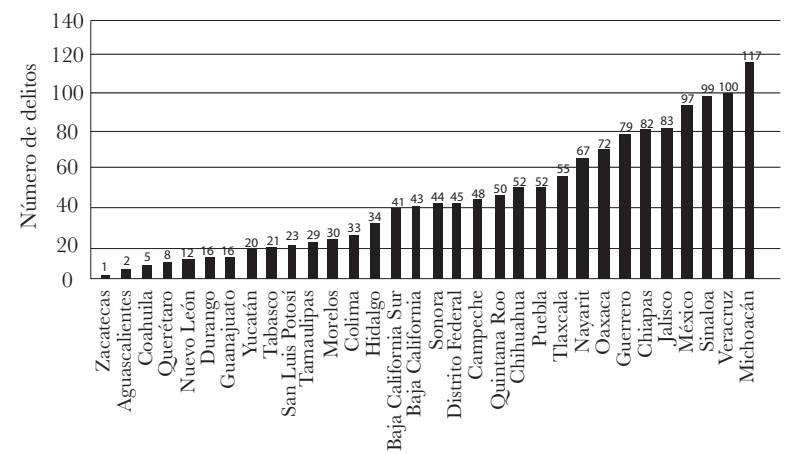

Estados de la República mexicana Total de datos: 1,476

Periodo: ene-dic 2009

FUENTE: elaboración propia.

Con respecto al estado de Oaxaca, éste cuenta con una geografía muy particular, ya que se ubica en intrincadas montañas y abruptas serranías, alineadas sobre la Sierra Madre Oriental, Sierra Madre del Sur y la Sierra atravesada, adosándose en una mayor complejidad geológica que es altamente sísmica. Constituye el estado con mayor diversidad de ecosistemas y biológicas del país con significativos cuerpos de agua representados en ríos preferentemente.

Oaxaca en 2012 ve resultados por la implementación del "Programa Operativo Anual" (en adelante POA), de la Procuraduría Federal de Pro-

32 Procuraduría Federal de Protección al Ambiente en su portal en la firma de convenios de colaboración para el combate a los delitos ambientales, disponible en: $h t t p: / /$ wrwe.profepa.gob.mx/innovaportal/v/5103/1/mx.wap/reactivan_profepa_y_pgr_convenio_de_cooperacion_para_combate_a_delitos_ambientales.html. 
tección al Ambiente, su objetivo es combatir el tráfico de especies de vida silvestre, haciendo cumplir con la ley en la protección de los recursos naturales, en una postura de "cero tolerancia" a la sociedad con productos o subproductos. Este programa ha producido resultados, por ejemplo, en la recuperación de ejemplares, huevos, productos y subproductos (pieles de peto, pares de aletas, etcétera) de la tortuga marina golfina (Lepidochelys olivácea), observando lo dispuesto por la NOM-059-SEMARNAT-2010, que especifica las especies en peligro de extinción que requieren protección especial, ${ }^{33}$ esto se ve reflejado en los índices delictivos de la Procuraduría (gráfica 8).

Un aspecto social importante, que resalta en la investigación, es la aparición de los indígenas en la comisión de delitos ambientales. Es noticia nacional ${ }^{34}$ que la Procuraduría en 2014 investiga a 801 indígenas por delitos federales, específicamente a 198 indígenas en Oaxaca, misma que encabeza la lista (representa el $24.7 \%$ de las denuncias). Por otro lado, la Procuraduría en 2003 crea la Unidad Especializada para la Atención de Asuntos Indígenas, mediante Acuerdo A/067/03, adscrita a la Subprocuraduría de Derechos Humanos, Prevención del Delito y Servicios a la Comunidad. Entre sus objetivos destacan: dar un trato humanista a los indígenas tomando en cuenta sus singularidades; visitar los centros de reinserción social, impartir seminarios, conferencias y gestionar beneficios de libertad anticipada. ${ }^{35}$

Del año de la creación de la Unidad Especializada para la Atención de Asuntos Indígenas de la Procuraduría hasta el detonante que se presenta (2014) existen once años de diferencia, en donde se presenta una gran área de oportunidad que la Procuraduría debe trabajar e investigar cuáles fueron los factores que la han acrecentado, ya que se ha disparado su incidencia y ha permitido que los indígenas se inclinen hacia las acciones delictivas ambientales a pesar del trabajo de prevención realizado.

33 Procuraduría Federal de Protección al Ambiente, disponible en: http://wrerw.profepa. gob.mx/innovaportal/v/4796/1/mx/la_profepa_asegura_mas_de_22_mil_huevos_de_tortuga_y_ pone_a_disposicion_del_mpf_a_2_presuntos_traficantes_por_su_posesion.html.

34 Periódico Excélsior en su apartado de noticias nacionales, disponible en: http://wrere. excelsior.com.mx/nacional/2014/12/30/1000114.

35 Procuraduría General de la República en su apartado de unidades especializadas para la atención de asuntos indígenas, disponible en: http://wwro.pgr.gob.mx/Unidades-Especializadas/ueaai/Paginas/default.aspx.

Esta obra está bajo una Licencia Creative Commons

Atribución-NoComercial-SinDerivar 4.0 Internacional, IIJ-UNAM.

Boletín Mexicano de Derecho Comparado, núm. 150, pp. 1083-1114 
Esta revista forma parte del acervo de la Biblioteca Jurídica Virtual del Instituto de Investigaciones Jurídicas de la UNAM

\section{GrÁfICA 8. Delitos ambientales, Oaxaca 2012}

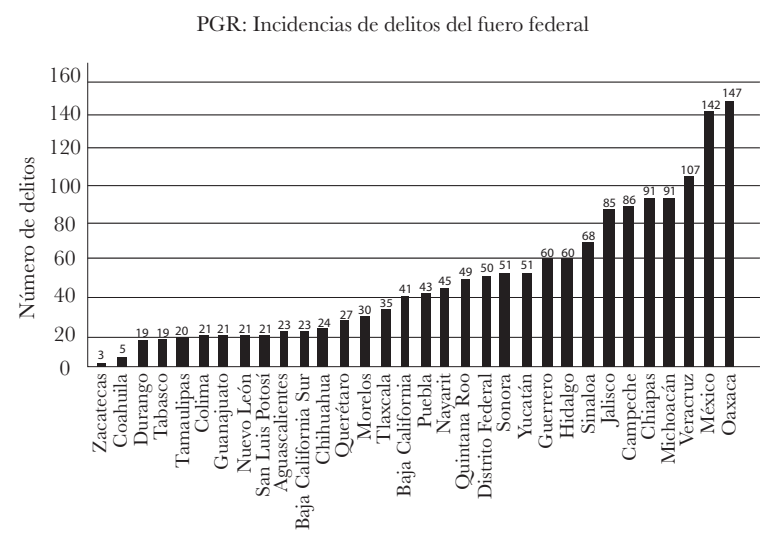

Estados de la República mexicana Total de datos: 1,579

Periodo: ene-dic 2012

FUENTE: elaboración propia.

Continuando con el análisis, Chiapas es un estado de la República que cuenta con una gran diversidad de recursos naturales. Lo que caracteriza a este estado es que es rico en su superficie forestal y aprovechamiento de maderas. En la selva lacandona cohabitan un $60 \%$ de las especies mexicanas de árboles tropicales; tiene 36 áreas naturales protegidas y 67 de control municipal, así como yacimientos petrolíferos, caudales hidrológicos, que generan de manera sustancial energía eléctrica en el país.

En 2008, el licenciado Juan Sabines Guerrero, en su carácter de gobernador del estado de Chiapas, en compañía de representantes del gobierno federal, Poder Ejecutivo, Legislativo y Judicial del estado, sector productivo, sociedad civil, asociaciones religiosas y medios de comunicación, dentro de la séptima sesión extraordinaria del Consejo Estatal de Seguridad Pública, firmaron un pacto denominado "Acuerdo por un Chiapas más Seguro". ${ }^{66}$ Dicho acuerdo tiene como objetivo conjuntar esfuerzos de todos los sectores sociales y culturales, y mantener el orden y la seguridad social, promoviendo el desarrollo integral como una "unidad".

36 Gobierno del estado de Chiapas, disponible en: http://wrere.uae.chiapas.gob.mx/ compendioLegislativo/Acuerdos/Acuerdo\%20por\%20un\%20Chiapas\%20a\%C3\%BAn\%20 $m \%$ C3\%A1s20seguro.pdf. 
Con base en este conjunto de esfuerzos se creó la Fiscalía para la Atención de los Delitos Ambientales (Fepada), perteneciente a la Procuraduría General de Justicia del Estado, institución que trabaja en coordinación con la Procuraduría, y tiene el objetivo de proteger a la sociedad y la familia que habitan dentro del territorio del estado, sobre las conductas ilícitas contrarias que atentan contra el patrimonio ecológico del estado. El trabajo coordinado de las diferentes instituciones explica la labor relevante que ha desempeñado este estado, en particular, en la cultura de la denuncia en 2013 y 2014 (gráficas 9 y 10).

Por otro lado, Jalisco en 2013 coincide con Chiapas dentro de sus esfuerzos para reforzar la cultura de la denuncia ambiental (gráficas 9 y 10). El estado cuenta con recursos naturales de diversa índole; se encuentra ubicado en el hemisferio sur; inicia con la Sierra Madre del Sur y cruza sobre el eje transversal neovolcánico. Cuenta con cuatro playas consideradas como zonas de reserva natural con base en la tortuga marina y otras especies. En su hábitat alberga un sinnúmero de flora y fauna endémica en peligro de extinción o de protección especial. Uno de sus cuerpos de agua representativos es el lago de Chapala, es considerado el más grande de Mesoamérica, y representa el 50\% del volumen lacustre de la nación.

En el año de referencia, en Jalisco se realizan trabajos simultáneos con la Profepa y la delegación de la Procuraduría en conjunto con la Unidad Especializada en Investigación de Delitos contra el Medio Ambiente y Previstos en Leyes Especializadas (UEIDAPLE). Dentro de los trabajos se destacan: solicitudes de órdenes de cateo para la verificación por parte de la Profepa en la inspección de empresas en la presunción de delitos ambientales, trabajos conjuntos de inteligencia, identificación de centros de acopio y venta ilegal de animales silvestres con apego a la NOM-059-SEMARNAT-2010 y otros. ${ }^{37}$ Esto detona en un incremento a la denuncia ambiental en el estado, ya que se da seguimiento constante a dichas diligencias en pro al medio ambiente.

Los delitos contra la biodiversidad con mayor reincidencia son la extracción de material pétreo (sobre explotación de piedras y material de los

37 Procuraduría Federal de Protección al Ambiente, disponible en: http://wrere.profepa.gob.mx/innovaportal/v/5558/1/mx/detiene_profepa_a_3_traficantes_y_asegura_contrabando_ de_441_aves_silvestres.html.

Esta obra está bajo una Licencia Creative Commons

Atribución-NoComercial-SinDerivar 4.0 Internacional, IIJ-UNAM.

Boletín Mexicano de Derecho Comparado, núm. 150, pp. 1083-1114 
Esta revista forma parte del acervo de la Biblioteca Jurídica Virtual del Instituto de Investigaciones Jurídicas de la UNAM http://www.juridicas.unam.mx/

bancos de arena), cambio de uso de suelo, uso y disposición de aguas sin tratamiento, cortar, arrancar o talar árboles en zonas prohibidas.

GrÁFICAS 9 y 10. Delitos ambientales

Chiapas y Jalisco 2013 y 2014

PGR: Incidencias de delitos del fuero federal

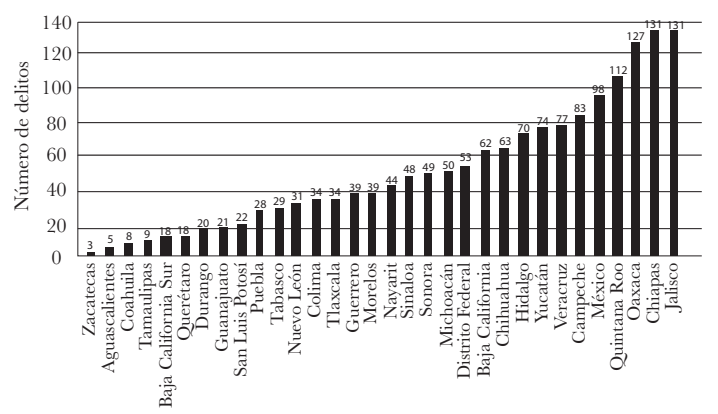

Estados de la República Total de datos: 1,630 Periodo: ene-dic 2013

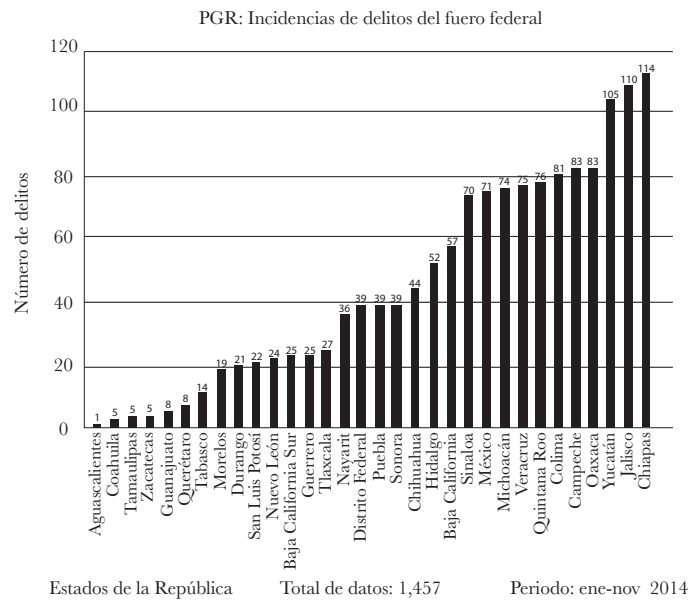

FUENTE: elaboración propia.

Podemos precisar que las entidades federativas que han representado con mayor eficiencia a la cultura de la denuncia ambiental, de 2007 a 2014, son Veracruz y Chiapas (tabla 1 y gráfica 11). Es interesante estudiar el comportamiento del modelo institucional de la Procuraduría, porque el presente

Esta obra está bajo una Licencia Creative Commons Atribución-NoComercial-SinDerivar 4.0 Internacional, IIJ-UNAM. Boletín Mexicano de Derecho Comparado, núm. 150, pp. 1083-1114 
Esta revista forma parte del acervo de la Biblioteca Jurídica Virtual del Instituto de Investigaciones Jurídicas de la UNAM http://www.juridicas.unam.mx/

análisis refleja estos reacomodos y cambios, aunados en un efecto directo de una genuina pretensión en la obtención de una justicia ambiental.

TABLA 1 Y GRÁFICA 11. Línea de tiempo en delitos ambientales 2007-2014

\section{Delitos ambientales PGR 2007-2014}

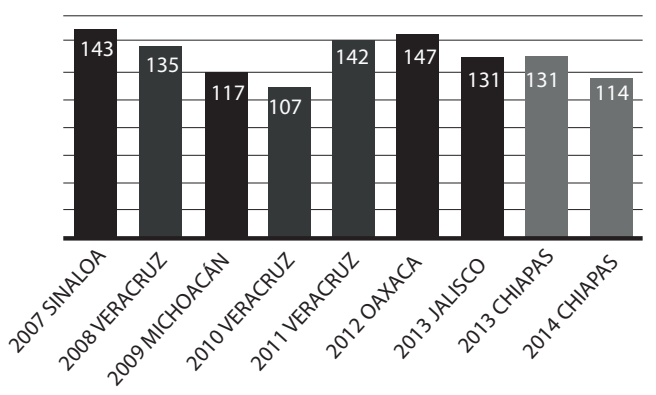

\begin{tabular}{|c|c|c|c|c|}
\hline Año & Estado & $\begin{array}{c}\text { Delitos } \\
\text { ambientales }\end{array}$ & Porcentaje anual & Delitos totales \\
\hline 2007 & Sinaloa & 148 & $10 \%$ & 1,397 \\
\hline 2008 & Veracruz & 135 & $8 \%$ & 1,692 \\
\hline 2009 & Michoacan & 117 & $8 \%$ & 1,476 \\
\hline 2010 & Veracruz & 107 & $8 \%$ & 1,491 \\
\hline 2011 & Veracruz & 142 & $9 \%$ & 1,692 \\
\hline 2012 & Oaxaca & 147 & $8 \%$ & 1,630 \\
\hline 2013 & Jalisco & 131 & $8 \%$ & 1,630 \\
\hline 2013 & Chiapas & 131 & $8 \%$ & 1,457 \\
\hline 2014 & Chiapas & 114 & Total & 14,044 \\
\hline
\end{tabular}

FUENTE: elaboración propia.

Esta obra está bajo una Licencia Creative Commons

Atribución-NoComercial-SinDerivar 4.0 Internacional, IIJ-UNAM.

Boletín Mexicano de Derecho Comparado, núm. 150, pp. 1083-1114 


\section{CONCLUSIONES}

1. El modelo institucional especializado tiene cabida sólo a finales del siglo XX y principios del XXI de nuestra era. La protección ambiental ha sido un tema que se ha tratado con muy poca importancia dentro de nuestro andamiaje institucional, y con gran dificultad se han ido modificando sus estructuras. Sin embargo, estos ajustes han permeado en un trabajo "especializado" en la procuración de justicia, rompiendo con los paradigmas actuales. El medio ambiente y su protección es un tema que a todos nos ocupa y preocupa. Hemos visto que cuando interviene directamente la participación social por parte de organizaciones privadas en coordinación con la intervención del andamiaje institucional del Estado, nuestra idea general de protección cambia y la postura antropocentrista queda de lado mostrando un interés genuino a nuestro entorno ecológico. Como consecuencia a esto, se da apertura a una mayor conciencia a la denuncia ambiental.

2. El trabajo preventivo de nuestras instituciones, a fin de estimular a la denuncia ambiental, se ha visto en un incremento en la mayoría de los sectores del país. La utilización de medios de comunicación, entrega de folletos, pláticas, conferencias y otros recursos, que se han usado a fin de sensibilizar a la gente para fomentar los trabajos conjuntos o tener una mayor participación social en los asuntos del Estado, pone en retrospectiva nuestra incidencia sobre una huella ecológica que trastoca sectores sensibles que determinan la sustentabilidad de los procesos productivos, sociales y políticos de nuestro país. Desafortunadamente, en el panorama se presentan agentes que por su propia naturaleza eran garantes en la protección de los recursos naturales, como es el caso de los "indígenas". Éstos cada vez más se van inclinando en la comisión de delitos ambientales y conductas contrarias a la ley. El Estado, a pesar de contar con unidades especializadas para su asistencia y manejo, se ha visto desplazado por infinidad de problemáticas que cuentan estos sectores de la población; por tanto, constituye una gran área de oportunidad para su investigación y análisis a fin de inhibir estas prácticas contrarias a nuestros recursos naturales.

3. Se pudo apreciar en la investigación que existe una mayor eficiencia en los trabajos realizados dentro de la misma "localidad". Más allá de la búsqueda de logros a nivel global, estos efectos han disminuido en las entidades federativas que se analizaron y se vieron reflejados en la estadís- 
tica de las denuncias ambientales. El modelo institucional se fue moldeando y remodelando, contando con un mayor conocimiento de la zona. La coordinación de las autoridades de los tres niveles de gobierno demostró un gran acierto a través de los convenios, trabajos conjuntos y coordinados, utilizando las herramientas que cada entidad posee para un bien común. Esto en el fomento de políticas públicas e instrumentos jurídicos que le den certeza legal a sus actuaciones. Tratadistas como Amartya Sen, premio Nobel de Economía, en su obra intitulada La idea de la justicia pone de manifiesto la identificación de las injusticias a fin de poder repararlas. Es menester, por tanto, identificarlas en cada entidad y ver las fortalezas existentes para que podamos aspirar a mejores modelos institucionales con la intervención de la participación social en la cultura de la denuncia ambiental.

\section{FUENTES}

Burgoa Orinuela, Ignacio, Las garantías individuales, México, Porrúa, 1983.

Castillo Soberanes, Miguel Ángel, El monopolio del ejercicio de la acción penal del Ministerio Público en México, México, UNAM, 1991.

Castro, Juventino, El Ministerio Público en México, funciones y disfunciones, México, Porrúa, 1993.

Excélsior (30 de diciembre de 2014), recuperado el 8 de septiembre de 2015, disponible en: http://wrewexcelsior.com.mx/nacional/2014/12/30/1000114.

FAIRÉN GILLÉN, Victor, Teoría general del derecho procesal, México, UNAM, 1992.

FiX-ZAMUdio, Héctor, Reflexiones sobre el derecho constitucional procesal mexicano, México, Comisión Nacional de Derechos Humanos, 1993.

Franco Villa, José, El Ministerio Público Federal, México, Porrúa, 1985.

García Ramírez, Sergio, Proceso penal y derechos humanos, México, Porrúa, 1993.

Gobierno DE Chiapas, Compendio legislativo (obtenido de Acuerdos 2008) disponible en: http://wrere.uae.chiapas.gob.mx/compendioLegislativo/Acuerdos/Acuerdo\%20por\%2 Oun\%20Chiapas\%20a\%C3\%BAn\%20 m\%C3\%A1s\%20seguro.pdf. 
GObIERNO DEL ESTADO DE VERAGRUZ (2005), SEFIPLAN (recuperado el 7 de octubre de 2015), Consejo Estatal de Protección al Ambiente, disponible en: http://wrerw.veracruz.gob.mx/finanzas/files/2012/01/tf07pepvdmedioambuente.pdf.

Instituto Nacional De Geografía, Consulta (obtenido de Procuraduría General de la República), disponible en: http://buscadorinegi.org. $m x /$ search $?$ tx $=P G R E^{2} q=P G R E^{2}$ site $=$ sitioINEGI_collection Eclient $^{\prime}=I N E G I$

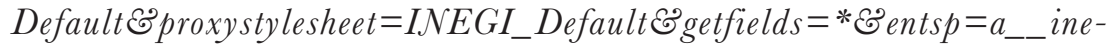
gi_politica $\mathcal{E}^{2}$ Proxyreload $=1$ Elr=lang_es $\% 257$ Clang_en $\mathcal{E}^{2} \mathrm{lr}=\mathrm{lang}_{-}$ es\%257Clang_en E̊filter $=1$.

Pallares, Jacinto, El Poder Fudicial, México, Imprenta del Comercio de Nabor Chávez, 1992.

Piña y Palacios, Javier, "Origen del Ministerio Público en México", $R e^{-}$ vista Mexicana de Fusticia, 1984.

Procuraduría Federal de Protecaión al Ambiente, Comunicación 2013 (recuperado el 8 de septiembre de 2015), disponible en: http:// wwr.profepa.gob.mx/innovaportal/v/5558/1/mx/detiene_profepa_a_3_ traficantes_y_asegura_contrabando_de_441_aves_silvestres.html.

, 2010 (recuperado el 13 de octubre de 2015), disponible en: http:// wrw.profepa.gob.mx/innovaportal/v/5103/1/mx.wap/reactivan_profepa_y_ pgr_convenio_de_cooperacion_para_combate_a_delitos_ambientales.html.

- 28 de diciembre de 2012, recuperado el 8 de septiembre de 2015, disponibl en: http://wrere.profepa.gob.mx/innovaportal/v/4796/1/mx/ la_profepa_asegura_mas_de_22_mil_huevos_de_tortuga_y_pone_a_disposicion_ del_mpf_a_2_presuntos_traficantes_por_su_posesion.html.

Procuraduría General De la República, 1 de enero de 2007, Portal histórico (recuperado el 7 de septiembre de 2015), disponible en: http:// archivo.pgr.gob.mx/Prensa/2007/bol07/Ene/b01007.shtm.

6 de julio de 2008, Portal histórico (recuperado el 13 de septiembre de 2015, de Boletín 552/08), disponible en: http://archivo.pgr.gob.mx/Prensa/2007/bol08/ful/b552\%2008.shtm.

, 15 de agosto de 2015, PGR (recuperado el 13 de octubre de 2015, de unidades especializadas), disponible en: http://wrerr.pgr.gob.mx/Unidades-Especializadas/ueaai/Paginas/default.aspx.

, Procuraduría General de la República, 14 de febrero de 2015 (obtenido de Incidencia delictiva del fuero federal (IDEF), disponible en: 
Esta revista forma parte del acervo de la Biblioteca Jurídica Virtual del Instituto de Investigaciones Jurídicas de la UNAM

http://wrew.pgr.gob.mx/temas\%20relevantes/estadistica/Incidencia\%20Entidad/IDEF.asp.

-, Unidad especializada (recuperado el 19 de agosto de 2015 de Unidad Especializada en Investigación de Delitos Contra el Ambiente y Previsto en Leyes Especiales), disponible en: http://wrerw.pgr.gob.mx/UnidadesEspecializadas/uedmatpa/Paginas/default.asx.

, Inicio (recuperado el 19 de agosto de 2015 de unidades especiali zadas), disponible en: http://wrere.pgr.gob.mx/Unidades-Especializadas/Paginas/default.aspx.

SECRETARÍA DE Gobernación, Archivos (recuperado el 13 de septiembre de 2015), disponible en: http://sil.gobernacion.gob.mx/Archivos/Documentos/2008/02/asun_2411656_20080212_1202840096.pdf.

Fecha de recepción: 15 de noviembre 2016

Fecha de aceptación: 08 de mayo de 2017

Esta obra está bajo una Licencia Creative Commons

Atribución-NoComercial-SinDerivar 4.0 Internacional, IIJ-UNAM.

Boletín Mexicano de Derecho Comparado, núm. 150, pp. 1083-1114 